Scientific journal

PHYSICAL AND MATHEMATICAL EDUCATION

Has been issued since 2013.

Науковий журнал

ФІЗИКО-МАТЕМАТИЧНА ОСВІТА

Видається з 2013.
ISSN 2413-158X (online)

ISSN 2413-1571 (print)

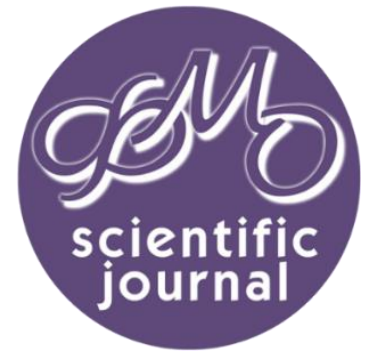

\title{
http://fmo-journal.fizmatsspu.sumy.ua/
}

Друшляк М.Г., Семеніхіна О.В. Організація автоматизованого контролю знань з використанням Plickers. Фізикоматематична освіта. 2019. Випуск 4(22). С. 28-35.

Drushlyak M., Semenikhina O. Organization of automated knowledge control with using Plickers. Physical and Mathematical Education. 2019. Issue 4(22). P. 28-35.

DOI 10.31110/2413-1571-2019-022-4-005

М.Г. Друшляк

Сумський державний педагогічний університет імені А.С.Макаренка, Україна marydru@fizmatsspu.sumy.ua

ORCID: 000-0002-9648-2248

О.В. Семеніхіна

Сумський державний педагогічний університет імені А.С. Макаренка, Україна e.semenikhina@fizmatsspu.sumy.ua ORCID: 0000-0002-3896-8151

\section{ОРГАНІЗАЦІЯ АВТОМАТИЗОВАНОГО КОНТРОЛЮ ЗНАНЬ 3 ВИКОРИСТАННЯМ PLICKERS}

\section{АНОТАЦІЯ}

Постановка проблеми. Однією з проблем, з якою стикаються викладачі закладів освіти України, є недостатня кількість комп'ютерів та обмежений доступ до комп'ютерних класів. Через че залучення цифрових технологій у освітній процес точкове - їх використовує або лише викладач, або студент вдома при виконанні самостійної роботи. В той же час молодь часто використовує власні мобільні пристрої не лише для спілкування в мережах, а й для підтримки власної освітньої діяльності. Тому актуальним є залучення власних мобільних пристроїв (смартфонів, планшетів, нетбуків тощо) в освітній процес. При організації автоматизованого контролю знань останнього часу популярними стають системи відповідей учнів/студентів (online formative assessment, audience response systems), cepeд яких найвідомішими є Clickers, Plickers, Kahoot ma Socrative. Водночас в Україні системного дослідження використання додатку Plickers в освітньому процесі, зокрема, у навчанні математики, не проведено, а тому наукові розвідки у цьому напрямі є актуальними. Мета: описати використання програмного засобу Plickers для організації автоматизованого контролю знань.

Матеріали і методи. У дослідженні використано теоретичні (узагальнення навчально-методичних джерел для обгрунтування актуальності проблеми дослідження; аналіз програмного забезпечення для вибору програми, використання якої забезпечить швидку i одночасно просту організацію автоматизованого контролю знань учнів), емпіричні (педагогічний експеримент для визначення ефективності використання обраного програмного забезпечення) та статистичні методи (критерій Стьюдента для порівняння середніх, критерій Макнамари для визначення позитивних зрушень у навчальних досягненнях) дослідження.

Результати. Нам потрібно було уточнити, чи потребує опитування з Plickers більше часу, ніж комп'ютерне тестування; буде чи не буде комп'ютерне тестування як форма контролю ідентичною до опитування з Plickers щодо оцінки результатів навчальних досягнень студентів. При опитування з Plickers студенти з низьким рівнем навчальних досягнень або флегматичним чи меланхолічним психотипом орієнтуються на швидкість відповідей студентів із високим та середнім рівнем навчальних досягнень, а тому часто відповідають бездумно. В умовах комп'ютерного тестування були зафіксовані випадки, коли час вже вичерпано, а студент ще не відповів на всі запитання тесту. 3 використанням технології Plickers така ситуація неможлива.Середній час комп'ютерного тестування визначається здебільшого темпом розв'язування задач більшості, тобто студентів із середнім рівнем навчальних досягнень. Середній час опитування з Plickers значною мірою залежить від темпу розв'язування задач студентами з високим рівнем навчальних досягнень. Форма контролю не впливає на розподіл студентів за рівнем їхніх навчальних досягнень.

Висновки. 1. $з$ огляду на проведений статистичний аналіз результатів варто рекомендувати Plickers як альтернативу комп'ютерному тестуванню, оскільки на нього (за умови попереднього опанування технологією організації та проходження тестування) витрачається менше часу, а результати є адекватними щодо рівня знань студентів. 2. Основними шляхами використання програми Plickers на уроках є фронтальне опитування наприкінці чи на початку уроку, проведення тестування, самостійних робіт. 3. Досвід використання додатку дозволяє описати переваги та недоліки організації контролю знань із використанням мобільного додатку Plickers.

КлючОвІ СлОвА: контроль, контроль знань, автоматизований контроль, контроль знань студентів, Plickers, освіта 


\section{ВСТУП}

Цифрова трансформація освітньої сфери - процес необхідний та незворотній. Про це наголошується у проекті закону «Цифрова адженда України - 2020» («Про цифровий порядок денний України - 2010») [1], який сьогодні запропоновано для обговорення українському суспільству і який корелює з ідеями перспективного портрету освіти XXI століття - Освіти 4.0. У Проекті зазначено про нагальну потребу перегляду навчальних програм закладів вищої освіти з метою впровадження цифрових технологій в освітній процес, що відповідають вимогам Індустрії 4.0. Застарілі методики викладання, недоступність цифрових технологій для навчального процесу призвели до надзвичайно низького рівня цифрової грамотності в усіх наявних сегментах державної системи освіти (дошкільної, початкової, середньої, вищої). Тому ідея впровадження цифрових технологій, зокрема, засобів автоматизованого контролю знань студентів наразі $\epsilon$ актуальною.

Однією з проблем, з якою стикаються викладачі закладів освіти України, є недостатня кількість комп'ютерів та обмежений доступ до комп'ютерних класів. Через це залучення цифрових технологій у освітній процес точкове - їх використовує або лише викладач, або студент вдома при виконанні самостійної роботи. В той же час молодь часто використовує власні мобільні пристрої не лише для спілкування в мережах, а й для підтримки власної освітньої діяльності. Тому актуальним $€$ залучення власних мобільних пристроїв (смартфонів, планшетів, нетбуків тощо) в освітній процес. Такий підхід отримав назву BYOD (Bring Your Own Device). Впровадження BYOD-підходу доцільно розглядати у межах мобільного навчання. Автори вже зверталися до проблеми впровадження BYOD-підходу при використанні хмарного cepвicy GeoGebra в навчанні природничо-математичних дисциплін [2].

Водночас використання мобільних додатків у рамках BYOD-підходу доцільно розглядати не тільки з позицій подання навчальної інформації, а також з позицій контролю знань студентів, серед яких відзначимо мобільний додаток Plickers.

При організації автоматизованого контролю знань останнього часу популярними стають системи відповідей учнів/студентів (online formative assessment, audience response systems), серед яких найвідомішими $€$ Clickers, Plickers, Kahoot та Socrative.

Програмний засіб Plickers порівняно з іншими програмами такого типу [3] має низку переваг, серед яких не останнє місце займає його вільне розповсюдження та простота у використанні. Зауважимо, що програма Clickers коштує близько 1000-1500 USD, кожен набір якої містить 32 картриджа для 32 студентів. Plickers $€$ вільно поширюваним програмним забезпеченням. Цей додаток простий у використанні, не потребує додаткових налаштувань на девайсах. Для роботи з Plickers потрібні роздруковані паперові картки і лише один мобільний телефон чи планшет для їх сканування. Відповіді студентів автоматично збираються, зберігаються, аналізуються на сайті компанії, і $є$ доступними викладачу.

Про доцільність та ефективність використання мобільного додатка Plickers наголошується у дослідженнях різних науковців. Зокрема, J. R. De Thomas, V. López-Fernández, F. Llamas-Salguero, P. Martín-Lobo and S. Pradas аналізували зв'язок між рівнем навчальних досягнень, ступенем залучення та креативністю студентів при використанні Plickers. Вони стверджують, що через активну участь у опитуванні за допомогою Plickers покращується якість знань студентів [4].

T. A. Wood, K. Brown and J. M. Grayson [5] досліджували сприйняття учнями старшої школи технології Plickers як методу контролю знань. Вони з'ясували, що така технологія покращує атмосферу в аудиторії, сприймається учнями як захоплююча, незвичайна і швидка в плані отримання результату тестування. Аналогічні результати було отримано S. Wuttiprom, K. Toeddhanya, A. Buachoom and K. Wuttisela [6].

M. G. McCargo [7] перевіряв вплив використання технології Plickers на поведінку учнів старшої школи та сприйняття вчителями середньої школи Plickers як соціально обґрунтованого методу боротьби з поведінкою учнів.

A. Gürişik [8] аналізували думки учнів середньої школи щодо використання Plickers та проблем учнів, що виникають при використанні цієї технології.

O. Demirkan, A. Gürişik and O. Akin [9] та E. A. Michael, I. E. A. Ejeng, M. A. Udit and M. M. Yunus [10] досліджували думки вчителів щодо використання Plickers у їх професійній діяльності.

Водночас в Україні системного дослідження використання додатку Plickers в освітньому процесі, зокрема, у навчанні математики, не проведено, а тому наукові розвідки у цьому напрямі $є$ актуальними.

Мета: описати використання програмного засобу Plickers для організації автоматизованого контролю знань.

\section{МАТЕРІАЛИ I МЕТОДИ}

У дослідженні використано теоретичні (узагальнення навчально-методичних джерел для обгрунтування актуальності проблеми дослідження; аналіз програмного забезпечення для вибору програми, використання якої забезпечить швидку і одночасно просту організацію автоматизованого контролю знань учнів), емпіричні (педагогічний експеримент для визначення ефективності використання обраного програмного забезпечення) та статистичні методи (критерій Стьюдента для порівняння середніх, критерій Макнамари для визначення позитивних зрушень у навчальних досягненнях) дослідження.

Експериментальною базою дослідження обрано Сумський державний педагогічний універистет, де навчалися студенти контрольної та експериментальної груп.

Освітній процес до 2017 року передбачав організацію контролю навчальних досягнень студентів у вигляді комп'ютерного тестування. 3 кожної теми були розроблені 20 тестових завдань з 4-ма варіантами відповідей на кожне. Комп'ютерне тестування проводилося наприкінці вивчення кожної теми. На нього відводилося 30 хвилин часу.

\section{РЕЗУЛЬТАТИ}

Нам потрібно було уточнити дві позиції: 1) чи потребує опитування з Plickers більше часу, ніж комп'ютерне тестування; 2) буде чи не буде комп'ютерне тестування як форма контролю ідентичною до опитування з Plickers щодо оцінки результатів навчальних досягнень студентів.

Педагогічний експеримент тривав протягом 2017-2019 рр. У ньому брала участь 101 особа, студенти спеціальності 014 Середня освіта (Математика та Інформатика). 
Після вивчення кожної теми (загальна кількість тем - 5) студенти проходили два контрольні заходи: комп'ютерне тестування і опитування із використанням Plickers. Запитання були подібні, змінювалися порядок розташування варіантів відповідей, порядок розташування самих завдань та числові значення вихідних даних умов задач.

Опишемо результати проведеного експерименту на прикладі результатів вивчення дисципліни «Математична логіка і теорія алгоритмів», де вивчалися:

Тема 1. Алгебра висловлень.

Тема 2. Числення висловлень.

Тема 3. Логіка предикатів.

Тема 4. Математичні теорії першого порядку.

Тема 5. Елементи теорії алгоритмів.

Статистична відмінність у часі проведення контрольних заходів

Статистична відмінність у часі проведення контрольних заходів перевірялася за критерієм Стьюдента (табл.1)

Середній час на виконання завдань (хв.)

\begin{tabular}{|c|c|c|c|c|c|}
\hline & Тема 1 & Тема 2 & Тема 3 & Тема 4 & Тема 5 \\
\hline Комп'ютерне тестування & 30 & 26 & 30 & 27 & 28 \\
\hline Plickers & 21 & 24 & 24 & 25 & 23 \\
\hline
\end{tabular}

Для опрацювання результатів використано табличний процесор Excel i пакет Аналіз даних (таблиця 2).

Результати аналізу середніх за критерієм Стьюдента

\begin{tabular}{|r|c|c|}
\hline & Переменная 1 & Переменная 2 \\
\hline Среднее & 28,2 & 5 \\
\hline Наблюдения & 5 & \\
\hline Гипотетическая разность средних & 0 & \\
\hline $\mathbf{d f}$ & 4 & \\
\hline $\mathbf{t}$-статистика & 3,638871 & \\
\hline $\mathbf{P}(\mathbf{T}<\mathbf{= t})$ одностороннее & 0,010993 & \\
\hline $\mathbf{t}$ критическое одностороннее & 2,131847 & \\
\hline $\mathbf{P}(\mathbf{T}<=\mathbf{t})$ двухстороннее & 0,021987 & \\
\hline $\mathbf{t}$ критическое двухстороннее & 2,776445 & \\
\hline
\end{tabular}

Одержані результати підтверджують статистичну розбіжність середнього часу на проведення комп'ютерного тестування (28,2 хв.) та опитування з Plickers $(23,4$ хв.).

Очевидним є менший розрив у середньому часі для тем 2 і 4, коли перевірялися здебільшого теоретичні знання. Більший розрив у середньому часі для тем 1 i 3, коли перевірялися вміння розв'язувати практичні завдання. Результати за темою 5 неоднозначні.

Скорочення середнього часу при опитуванні з Plickers пояснюємо особливістю використання такої технології фіксація відповідей студентів відбувається миттєво, як і зміна запитань на екрані, тоді як при комп'ютерному тестуванні кожен студент у власному темпі відповідає на запитання.

При опитування з Plickers студенти з низьким рівнем навчальних досягнень або флегматичним чи меланхолічним психотипом орієнтуються на швидкість відповідей студентів із високим та середнім рівнем навчальних досягнень, а тому часто відповідають бездумно.

В умовах комп'ютерного тестування були зафіксовані випадки, коли час вже вичерпано, а студент ще не відповів на всі запитання тесту. 3 використанням технології Plickers така ситуація неможлива.

Середній час комп'ютерного тестування визначається здебільшого темпом розв'язування задач більшості, тобто студентів із середнім рівнем навчальних досягнень. Середній час опитування з Plickers значною мірою залежить від темпу розв'язування задач студентами з високим рівнем навчальних досягнень.

Вплив форми контролю на результати навчання

Вплив форми контролю на результати навчання перевірявся за критерієм Макнамари.

Здійснення контролю передбачалося на одному і тому ж матеріалі: спочатку студенти проходили комп'ютерне тестування, потім на тому ж наборі запитань та відповідей проводилося опитування з використанням Plickers. Ha основі результатів студенти розподілялися на дві категорії: засвоїв - не засвоїв. До першої групи відносилися студенти, що відповіли правильно на 13 і більше запитань. Інших студентів було віднесено до другої групи.

Результати двократного контролю знань студентів представляють вимірювання за шкалою «Так - Ні». Результати представлено у таблиці 3. 
Результати двократного контролю знань студентів

\begin{tabular}{|c|c|c|c|c|}
\hline & & \multicolumn{2}{|c|}{$\begin{array}{c}\text { Результати } \\
\text { із використанням plickers }\end{array}$} & \\
\hline & & Засвоїв & Не засвоїв & \\
\hline \multirow{2}{*}{$\begin{array}{c}\text { Результати } \\
\text { комп'ютерного } \\
\text { тестування }\end{array}$} & Засвоїв & A & B & $A+b$ \\
\hline & Не засвоїв & C & D & $C+d$ \\
\hline & & $A+C$ & $B+d$ & $A+b+c+$ \\
\hline
\end{tabular}

За цих умов можливе застосування критерія Макнамари для виявлення значущості різниці у розподілі студентів за рівнем навчальних досягнень.

Перевіряється гіпотеза $\mathrm{H}_{0}$ : форма контролю не впливає на розподіл студентів за рівнем їхніх навчальних досягнень. Тоді альтернативна гіпотеза На формулюється наступним чином: розподіл студентів за рівнем їхніх навчальних досягнень залежить від обраної форми контролю. За цих умов для перевірки гіпотези застосовується двосторонній критерій

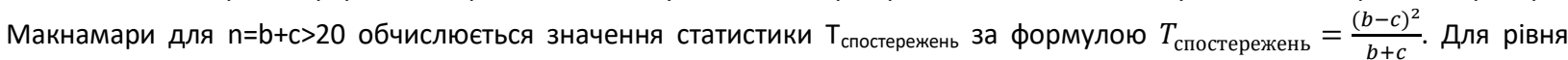
значущості $\alpha=0,05$ маємо критичне значення $\mathrm{T}_{\text {критич }}=3,84$.

У таблиці 4 наведено результати для 2017, 2018, 2019 років за темою 1.

Табличя 4

Результати педагогічного експерименту за критерієм Макнамари

\begin{tabular}{|c|c|c|c|c|c|c|}
\hline Рік & a & b & с & d & Тспостережень & Примітка \\
\hline $\mathbf{2 0 1 7}$ & 51 & 14 & 25 & 11 & 3,10 & Приймається $\mathrm{H}_{0}$ \\
\hline $\mathbf{2 0 1 8}$ & 57 & 10 & 16 & 18 & 1,38 & \\
\hline $\mathbf{2 0 1 9}$ & 62 & 11 & 16 & 12 & 0,92 & \\
\hline
\end{tabular}

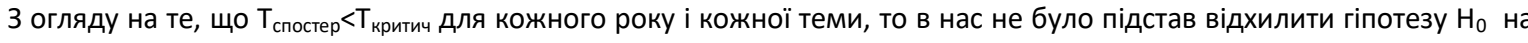
рівні значущості $\alpha=0,05$.

Це означає, що форма контролю не впливає на розподіл студентів за рівнем їхніх навчальних досягнень.

\section{ОБГОВОРЕННЯ}

Використання додатку Plickers не потребує особливої технічної та методичної підготовки.

Щоб почати користуватися додатком, потрібно зареєструватися на сайті http://plickers.com і ввести за алфавітом список групи (+New Class).

Далі до кожної групи потрібно прикріпити відповідні тести, тобто додати тести у так звану чергу (Add to Queue). Черга - це послідовність запитань, які потрібно задати студентам групи на найближчому занятті. Після того як запитання вже задане, то воно видаляється з черги. Кожного разу необхідно поновлювати чергу потрібних запитань.

Викладач роздруковує картки. Макети карток доступні для скачування на офіційному сайті у розділі Help/ Get Plickers Cards. Пропонується 5 різних наборів карток, кожна картка унікальна і має свій власний номер, який відповідає номеру студента у списку. Тому опитування є персоніфікованим.

Кожній стороні картки відповідає окремий варіант відповіді - A, B, C, D (рис. 1). Картки можуть використовуватися при кожному тестуванні, тому варто роздруковувати їх на цупкому папері.

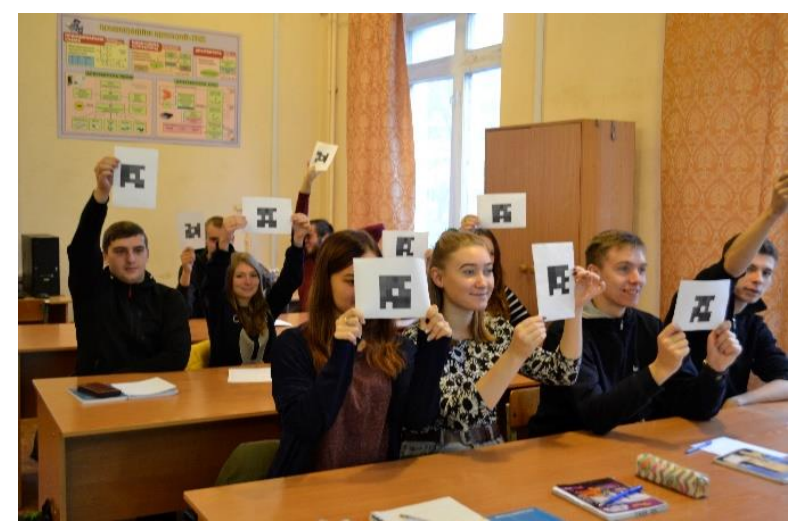

Рис. 1. Студенти відповідають на запитання 
Викладач заздалегідь повинен завантажити на мобільний телефон додаток Plickers. В ході проведення тестування викладачу потрібно зайти на власну сторінку і обрати групу та тест. В цей же час на комп'ютері на сайті потрібно обрати режим Now Playing.

Викладач ставить запитання (паралельно запитання висвічується на екрані та у мобільному телефоні). Запитання можна обрати з мобільного телефону, тобто викладач не повинен весь час знаходитися біля комп'ютера, все управління ведеться з телефону (рис. 2).

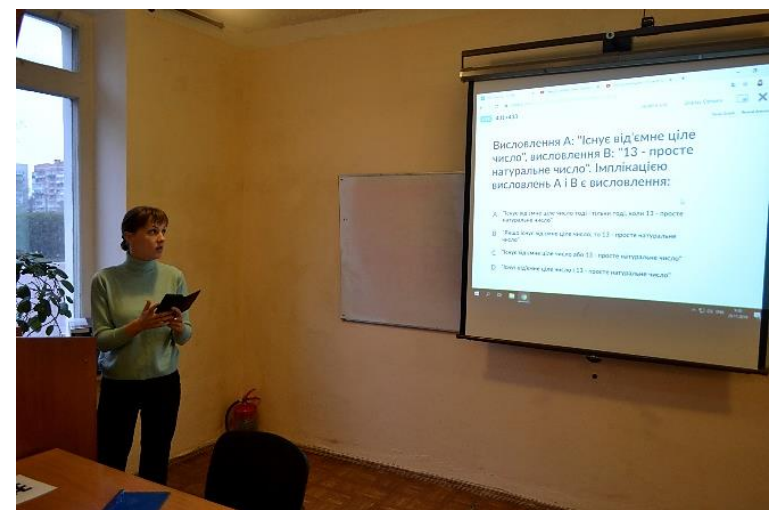

Рис. 2. Викладач зачитує запитання

Студенти, обравши відповідь, піднімають картки відповідними сторонами догори. За допомогою мобільного додатку викладач сканує відповіді студентів у режимі реального часу і результати зберігаються у базі даних (рис. 3). Студент може змінити свою відповідь, але зараховуватиметься тільки та, яка була у момент сканування.

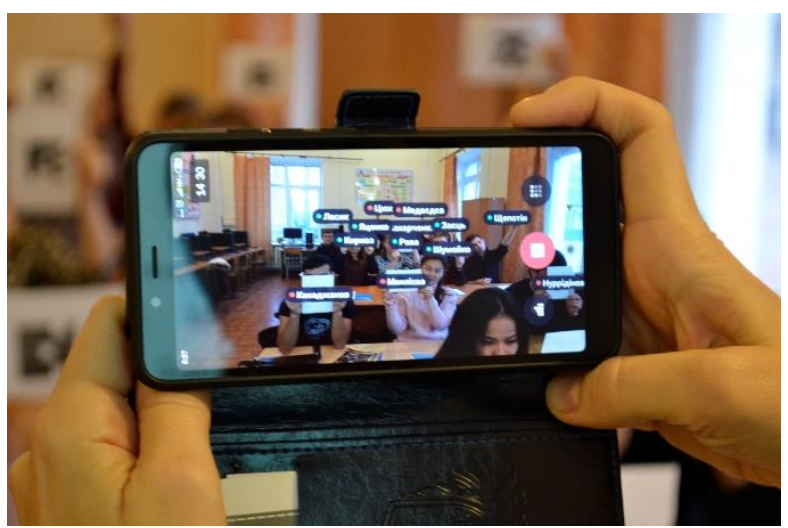

Рис. 3. Сканування відповідей студентів

Результати доступні як у мобільному додатку, так і на сайті (на екрані) для миттєвого оголошення і опрацювання (Scoresheet) (рис. 4).

\begin{tabular}{|c|c|c|c|c|c|c|}
\hline Name $\wedge$ & Total & $\begin{array}{c}\text { Які з } \\
\text { наступних } \\
\text { тверджень не }\end{array}$ & $\begin{array}{l}\text { Висловлення } \\
\text { А: "Існує } \\
\text { відемне ціле }\end{array}$ & $\begin{array}{l}\text { двох } \\
\text { висловлень - } \\
\text { це }\end{array}$ & $\begin{array}{c}\text { Яка логічна } \\
\text { операція } \\
\text { позначається }\end{array}$ & 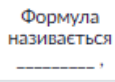 \\
\hline Class Average & $\bullet 51 \%$ & $60 \%$ & $73 \%$ & $53 \%$ & $67 \%$ & $7 \%$ \\
\hline Бакганов & & - & - & - & - & - \\
\hline Гаррибаєв & & - & - & - & - & - \\
\hline Джуманазаров & $\cdot 30 \%$ & $\mathrm{~A}$ & A & C & $D$ & C \\
\hline Диченко & & - & - & - & - & - \\
\hline Захарченко & $.65 \%$ & B & B & D & B & $B$ \\
\hline Заєць & $.65 \%$ & B & B & D & B & B \\
\hline Какаджанов & $\bullet 15 \%$ & $D$ & B & C & A & $A$ \\
\hline Кирноз & $.65 \%$ & B & $D$ & D & B & $B$ \\
\hline
\end{tabular}

Рис. 4. Деталізовані результати тестування

Викладач може також роздрукувати результати тестування як для всієї групи (Reports) (рис. 5), так і для кожного окремого студента для проведення роботи над помилками (Students Reports або попередньо натиснувши на прізвищі студента). Таблицю з результатами можна експортувати у файл MS Exel (Export Data to CSV). 


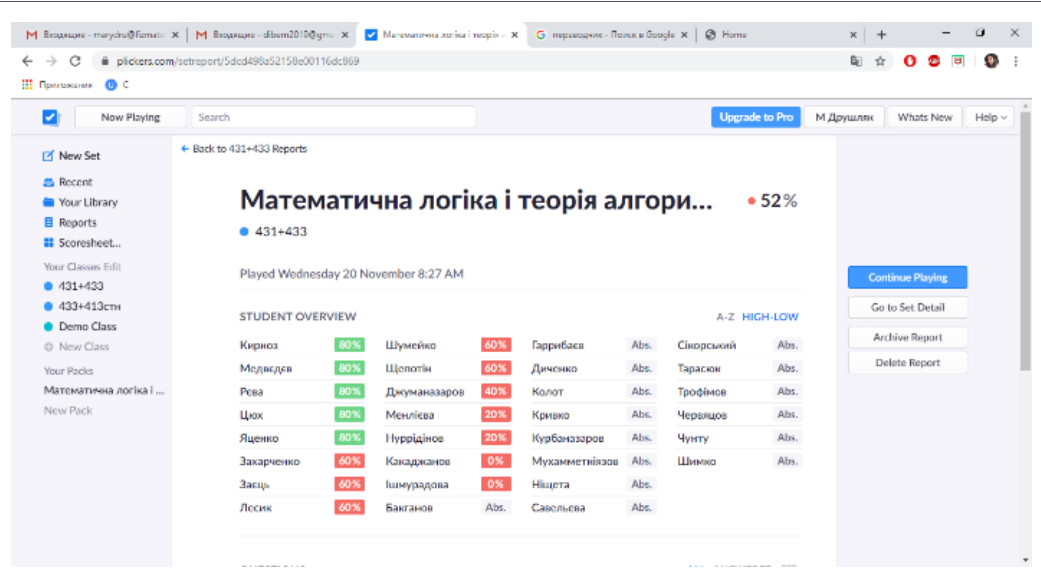

Рис. 5. Результати тестування

\section{висновки}

1. 3 огляду на проведений статистичний аналіз результатів варто рекомендувати Plickers як альтернативу комп'ютерному тестуванню, оскільки на нього (за умови попереднього опанування технологією організації та проходження тестування) витрачається менше часу, а результати $€$ адекватними щодо рівня знань студентів.

2. Основними шляхами використання програми Plickers на уроках $€$ фронтальне опитування наприкінці чи на початку уроку, проведення тестування, самостійних робіт.

3. Досвід використання додатку дозволяє описати переваги та недоліки організації контролю знань із використанням мобільного додатку Plickers.

- Організаційні переваги:

- простота у користуванні (simplicity);

- безкоштовність (free);

- не потребує попередньої підготовки студентів (does not demand student training to be used);

- не потрібує наявності мобільних телефонів студентів, потрібен тільки мобільний пристрій викладача;

- картки для відповідей багаторазові (can be reused).

- Серед організаційних недоліків програми Plickers саме з позицій використання на уроках математики можна виділити:

- неможливість вставки формул у текст запитання чи відповідей (лише у вигляді рисунків у текст запитання);

- лише два типи запитань із закритим типом відповідей - одиночний вибір та встановлення істинності чи хибності твердження (multiply choice or true/false format);

- один тест може містити максимум п'ять запитань, отже, вчителю потрібно буде створити декілька тестів і провести їх один за одним. При цьому результати надаються як для окремого тесту, так і для проведеної серії тестів;

- потрібен стабільний канал виходу в мережу, як на комп'ютері, так і на мобільному телефоні;

- не підходить для великих студентських груп, коли камера телефону не може зафіксувати усі картки з відповідями.

- Методичні переваги:

- використання Plickers інтенсифікує процес навчання, привносить елементи інтерактивності у процес контролю;

- д для студентів це своєрідна розвага (fun);

- викладач відразу бачить, хто з студентів відповів правильно, а хто - ні;

- студенти можуть змінити свою відповідь, зафіксується лише та відповідь, що була у момент сканування;

- студенти не бачать відповідей інших;

- результати тестування миттєві, вони зібрані у таблиці як для студентів усієї групи, так і для кожного студента окремо;

- для кожного студента можна роздрукувати результати тестування за кожним запитанням для проведення роботи над помилками.

- Методичні недоліки:

- $\quad$ не підходить для дистанційного навчання (cannot be employed in distance education, only face-to-face education).

1. Цифрова адженда України - 2020. [Electronic resource]. Retrieved from https://ucci.org.ua/uploads/files/58e78ee3c3922.pdf [in Ukrainian].

2. Семеніхіна О.В., Друшляк М.Г., Хворостіна Ю.В., (2019). Викорситання сервісу GeoGebra у підготовці вчителів математики Інформаційні технології і засоби навчання. Том 73, № 5. С. 48-66, 2019, DOI: https://doi.org/10.33407/itlt.v73i5.2500.

3. Plickers. [website]. Retrieved from http://plickers.com. [in English].

4. J. R. De Thomas, V. López-Fernández, F. Llamas-Salguero, P. Martín-Lobo and S. Pradas, (2016). “Participation and knowledge through Plickers in high school students and its relationship to creativity". In UNESCO-UNIR ICT \& Education Latam Congress, pp. 113-123 [in English].

5. T. A. Wood, K. Brown and J. M. Grayson, (2017). "Faculty and student perceptions of Plickers". In ASEE Zone II Conference. Retrieved from http://zone2.asee.org/sessions/program/3/84.pdf [in English]. 
6. S. Wuttiprom, K. Toeddhanya, A. Buachoom and K. Wuttisela, (2017). "Using Plickers cooperate with Peer Instruction to promote students' discussion in Introductory Physics Course". Universal Journal of Educational Research, 5(11), pp. 19551961. https://doi.org/10.13189/ujer.2017.051111 [in English].

7. M. G. McCargo, (2017). "The Effects of Plickers As Response Cards On Academic Engagement Behavior In High School Students". Master's Thesis. College of Education and Psychology, University of Southern Mississippi. Retrieved from http://aquila.usm.edu/masters_theses/300 [in English].

8. A. Gürişik, (2019). "Opinions of high school students about plickers: one of the online formative assessment tools." International Journal of Scientific Research and Innovative Technology, vol. 6, no. 1, January 2019, pp. 11-25[in English].

9. O. Demirkan, A. Gürişik and O. Akin, (2017). "Teachers' Opinions About "Plickers" One Of The Online Assessment Tools." Educational Research And Practice. Retrieved from https://www.researchgate.net/profile/Gokhan_Duman/publication/326902788_Educational_Research_and_Practice/links /5b6b1c2f45851546c9f6d0e7/Educational-Research-and-Practice.pdf\#page=484 [in English].

10. E. A. Michael, I. E. A. Ejeng, M. A. Udit and M. M. Yunus, (2019). "The Use of Plickers for Language Assessment of Reading Comprehension." International Journal of Academic Research in Business and Social Sciences, 9(1), pp. 637-645. [in English].

1. Цифрова адженда України _ $\begin{gathered}\text { References } \\ \text { 1. } 2020 .\end{gathered}$

https://ucci.org.ua/uploads/files/58e78ee3c3922.pdf [in Ukrainian].

2. O. Semenikhina, M. Drushliak and Yu. Khvorostina, (2019). "Use of GeoGebra cloud service in future math teachers' teaching," Information technologies and learning tools, vol. 73, no 5. pp. 48-66, 2019, DOI: https://doi.org/10.33407/itlt.v73i5.2500, [in Ukrainian].

3. Plickers. [website]. Retrieved from http://plickers.com. [in English].

4. J. R. De Thomas, V. López-Fernández, F. Llamas-Salguero, P. Martín-Lobo and S. Pradas, (2016). “Participation and knowledge through Plickers in high school students and its relationship to creativity". In UNESCO-UNIR ICT \& Education Latam Congress, pp. 113-123 [in English].

5. T. A. Wood, K. Brown and J. M. Grayson, (2017). "Faculty and student perceptions of Plickers". In ASEE Zone II Conference. Retrieved from http://zone2.asee.org/sessions/program/3/84.pdf [in English].

6. S. Wuttiprom, K. Toeddhanya, A. Buachoom and K. Wuttisela, (2017). "Using Plickers cooperate with Peer Instruction to promote students' discussion in Introductory Physics Course". Universal Journal of Educational Research, 5(11), pp. 19551961. https://doi.org/10.13189/ujer.2017.051111 [in English].

7. M. G. McCargo, (2017). "The Effects of Plickers As Response Cards On Academic Engagement Behavior In High School Students". Master's Thesis. College of Education and Psychology, University of Southern Mississippi. Retrieved from http://aquila.usm.edu/masters_theses/300 [in English].

8. A. Gürişik, (2019). "Opinions of high school students about plickers: one of the online formative assessment tools." International Journal of Scientific Research and Innovative Technology, vol. 6, no. 1, January 2019, pp. 11-25[in English].

9. O. Demirkan, A. Gürişik and O. Akin, (2017). "Teachers' Opinions About "Plickers" One Of The Online Assessment Tools." Educational Research And Practice. Retrieved from https://www.researchgate.net/profile/Gokhan_Duman/publication/326902788_Educational_Research_and_Practice/links /5b6b1c2f45851546c9f6d0e7/Educational-Research-and-Practice.pdf\#page=484 [in English].

10. E. A. Michael, I. E. A. Ejeng, M. A. Udit and M. M. Yunus, (2019). "The Use of Plickers for Language Assessment of Reading Comprehension." International Journal of Academic Research in Business and Social Sciences, 9(1), pp. 637-645. [in English].

\section{ORGANIZATION OF AUTOMATED KNOWLEDGE CONTROL WITH USING PLICKERS M.G. Drushlyak, O.V. Semenikhina}

Makarenko Sumy State Pedagogical University, Ukraine

Abstract.

Formulation of the problem. One of the problems that teachers of educational institutions of Ukraine face is the lack of computers and limited access to computer classes. Because of this, the involvement of digital technologies in the educational process is a point - they are used either only by the teacher or the student at home when doing their own work. At the same time, young people often use their own mobile devices not only to communicate on networks, but also to support their own educational activities. Therefore, it is important to involve your own mobile devices (smartphones, tablets, netbooks, etc.) in the educational process. When organizing automated knowledge control and online assessment, audience response systems are becoming more popular lately, with Clickers, Plickers, Kahoot, and Socrative being the most popular. At the same time, a systematic study of the use of the Plickers application in the educational process, in particular, in mathematics teaching, has not been conducted in Ukraine, and therefore scientific research in this area is relevant. Objective: To describe the use of Plickers software for the organization of automated knowledge control.

Materials and methods. The study used theoretical (generalization of educational and methodological sources to substantiate the relevance of the research problem; analysis of software to select a program, the use of which will provide a quick and simple organization of automated control of students' knowledge), empirical (pedagogical experiment to determine the effectiveness of using the selected software) and statistical methods (Student's $t$ test for comparing averages, McNamara's criterion for determining positive learning shifts nyh achievements) study.

Results. We needed to clarify whether the Plickers survey needed more time than computer-based testing; there will or may not be computer testing as a form of control identical to the Plickers survey for evaluating student learning outcomes. When interviewing with Plickers, students with low educational attainment or a phlegmatic or melancholy psychotype are guided by the response rate of high-and intermediate-achieving students, and are often thoughtlessly answered. In computer testing, there have been cases where time is running out and the student has not yet answered all of the test questions. With the use of the technology of Clickers such situation is impossible. The average time of computer-based testing is largely determined by the pace of completion of the tasks of the majority, ie students with average educational attainment. The average interview time with Plickers depends largely on the pace of 
problem solving for students with high levels of academic achievement. The form of control does not affect the distribution of students by the level of their academic achievement.

Conclusions. 1. Given the statistical analysis of the results, it is advisable to recommend Plickers as an alternative to computer-based testing, since it (with prior mastery of organization technology and testing) takes less time and results to be adequate to the students' level of knowledge. 2. The main ways to use the Plickers program in the classroom is to take a front-end survey at the end or at the beginning of the lesson, to conduct testing, to do individual work. 3. Application experience describes the advantages and disadvantages of organizing knowledge control using the Plickers mobile application.

Keywords: control, knowledge control, automated control, student knowledge control, Plickers, education. 